\title{
A novel approach for qualitative biosensing of anti-leptospiral IgG antibodies in human sera using functionalised silver nanoparticles
}

\author{
MH Dahanayake ${ }^{1,4}$, CD Gamage 2 , NMS Sirimuthu ${ }^{3}$ and ACA Jayasundera ${ }^{1,4 *}$ \\ ${ }^{I}$ Postgrudute Institute of Science, University of Peradeniya, Peradeniya. \\ ${ }^{2}$ Department of Microbiology, Faculty of Medicine, University of Peradeniya, Peradeniya. \\ ${ }^{3}$ Department of Chemistry, Faculty of Applied Sciences, University of Sri Jayewardenepura, Nugegoda. \\ ${ }^{4}$ Department of Chemistry, Faculty of Science, University of Peradeniya, Peradeniya.
}

Submitted: 28 November 2019; Revised: 25 June 2020; Accepted: 23 September 2020

\begin{abstract}
Nanoparticles can interact with biological molecules, thus broadening the applications in the field of medicine. Surface plasmon resonance of nanoparticles in ultraviolet-visible (UV-visible) region can be applied to identify nanoparticleprotein interactions. This property is used to detect antibodies against leptospirosis, which is an emerging infectious zoonosis in many developing countries and endemic in Sri Lanka. A rapid screening test to detect anti-leptospiral antibodies in human sera by analysing antigen-antibody interactions using UV-visible spectroscopy is reported. The protocol uses hydroxylamine hydrochloride stabilised silver nanoparticles followed by functionalisation with rLigA (recombinant leptospiral immunoglobulin-like protein A) antigens. rLigA-functionalised silver nanoparticles were characterised by UV-visible spectroscopy, dynamic light scattering (DLS), Fourier transform infrared (FT-IR) spectroscopy and scanning electron microscopy (SEM). A monodispersed solution of LigA-functionalised silver nanoparticles was prepared at $25^{\circ} \mathrm{C}$ and $\mathrm{pH} 7.0$ with optimum LigA concentration of $1.5 \mu \mathrm{g} \mathrm{mL}^{-1}$. This localised surface plasmon resonance (LSPR) biosensor shows a positive response to anti-leptospiral IgG antibodies at optimum conditions in dilutions lower than 1:25 ( $\mathrm{SD}= \pm 0.047$; $95 \% \mathrm{CI}=1.100-1.126)$. The dilutions, $1: 300$ to $1: 50$ of $\mathrm{IgG}$ antibodies maintained no response compared to the nanoparticle conjugate. Furthermore, the non-responsive UV-visible spectra of nanoparticle conjugate with anti-leptospiral antibody negative serum samples confirmed that the conjugate was specific to anti-leptospiral antibodies ( $\mathrm{SD}= \pm 0.012 ; 95 \% \mathrm{CI}=1.177-$ 1.183). This novel technique offers substantial improvement in terms of screening time, which does not take more than 30
\end{abstract}

minutes, compared to conventional methods such as ELISA consumes 2-3 hours.

Keywords: Anti-leptospiral antibodies, functionalisation, leptospirosis, localised surface plasmon resonance, nanoparticles, UV-visible spectroscopy.

\section{INTRODUCTION}

In the $20^{\text {th }}$ century, the fields of medicine and pharmaceuticals have been revolutionised with the advancement of nanotechnology, introducing nanomedicine as the latest innovation in the field of science (Watkins et al., 2015; Manatunga et al., 2018; Patra et al., 2018; Karunaratne et al., 2019). Nanoparticles can interact with biological molecules which are in nano-range, thus broadening the applications in the field of medicine (Wang et al., 2009). Metallic nanoparticles have unique morphologies, surface plasmon characteristics, quantum confinement, shortrange ordering, physicochemical properties and large surface energies (Blackman, 2008). The characteristics of metallic nanoparticles depend on their size, shape, crystallinity, structure and dielectric constant of the medium, leading to many studies and applications. These parameters can be changed or controlled to achieve desired properties of nanoparticles (Blackman, 2008).

"Corresponding author (acaj@pdn.ac.lk; iD https://orcid.org/0000-0002-6804-1808) 
Metallic nanoparticles can be modified using various chemical functional groups which allow them to conjugate with nucleic acids, ligands, proteins and drugs of interest, enabling detection and manipulation and providing good stability. This opens a variety of potential applications in biotechnology and medicine such as magnetic separation (Hola et al., 2015), biosensing (George et al., 2018), targeted drug delivery (Kumari et al., 2016), vehicles for gene and drug delivery (Maiyo \& Singh, 2017), drug encapsulation (Wais et al., 2016) and diagnostic imaging (Soloviev, 2004; Nikalje, 2015; Karunaratne et al., 2019).

Metallic nanoparticles, especially silver and gold nanoparticles, possess excellent optical properties such as localised surface plasmon resonance (LSPR), surfaceenhanced Raman scattering (SERS), fluorescence, etc. Silver nanoparticles possess the highest capacity of plasmon excitation among metallic nanoparticles, which show plasmon resonance in the visible range (Priyanka et al., 2013). LSPR wavelength and width depend on particle size, shape, medium and surface coating. The influences of above features, such as the binding of specific analytes on nanoparticle surface which alters the dielectric environment of the nanoparticle, can be identified by the colour change of solution or LSPR peak shift of absorption band (Hong et al., 2012). Peak shift can be measured using UV-visible spectrophotometer.

Leptospirosis is recognised as the most widespread bacterial zoonosis (Cosson et al., 2014). It is a major public health problem in many developing countries and endemic in India, Thailand, Indonesia and Sri Lanka. The disease occurs worldwide throughout the year with a seasonal distribution and causes morbidity and mortality in regions with high rainfall and high temperature, especially tropical and subtropical areas (Pappas et al., 2008). Current statistics assert that the annual worldwide cases of leptospirosis are above one million (Cosson et al., 2014).

Leptospirosis, caused by pathogenic Leptospira spps., is known as an acute febrile illness with a wide clinical spectrum which ranges from a mild, influenzalike illness to a critical infection such as renal failure, hepatic failure, pulmonary distress, jaundice (icterus) and also death, referred to as the classical Weil's disease (Fraga et al., 2014). Clinical diagnosis of leptospirosis is rather difficult as the symptoms are nonspecific. Diseases such as influenza, dengue, Hantavirus infection, yellow fever, malaria and hepatitis should be considered in the differential diagnosis and laboratory tests should be carried out to confirm the infection (Toyokawa et al.,
2011). The diagnosis can be performed by detecting antibodies or nucleic acids, by culturing or by verifying the presence of bacteria in tissues (Budihal \& Perwez, 2014; Chirathaworn et al., 2014; Khaki, 2016).

Diagnosis of most of the cases are done through serology. ELISA is one such serological test, which can detect IgM and IgG antibodies in human sera, indicating current/ recent infection and exposure to pathogen/ past infection, respectively (Khaki, 2016). ELISA detects the presence of proteins by colour change, which can be identified by the naked eye. However, some ELISA tests are low in specificity and positive results for the disease may be observed due to the presence of other antibodies as well (WHO, 2003). Therefore, PCR (polymerase chain reaction) or MAT (microscopic agglutination test) can be used along with ELISA to confirm the diagnosis (Budihal \& Perwez, 2014). Furthermore, ELISA requires several washing steps and incubation steps, which are time consuming, extending the analysis up to 3 to 5 hours. Thus, an alternative method to overcome the limitations of this diagnostic technique is required.

Nanoparticle-based immunoassays contribute to diagnostic systems for rapid and efficient identification of many diseases due to the unique properties of nanoparticles. In this study, a rapid screening test (detection of $\operatorname{IgG}$ does not confirm acute disease but past infection) to detect anti-leptospiral antibodies by analysing antigen-antibody interactions using silver nanoparticles was developed, which can be used for population-based screening purposes. UV-visible spectroscopy was used as the principal analysis method and dynamic light scattering (DLS), Fourier transforminfrared (FT-IR) spectroscopy and scanning electron microscopy (SEM) were used for the characterisation. Different environmental parameters that might affect the conjugation between silver nanoparticles and antigens, such as temperature, $\mathrm{pH}$ and protein concentration, were investigated in advance. Furthermore, antigen-coated silver nanoparticles were tested with anti-leptospiral antibodies to obtain the detection limit and sensitivity of the developed system. The formation of aggregates upon the addition of anti-leptospiral antibodies was identified by the decrement of UV-visible absorption peak and the increment of hydrodynamic diameter. Here, the antibody capturing by antigens is critical and depends on the immobilisation strategy. Conjugation between the nanoparticle and antigen should be stable and the antigens should be in biologically active molecular conformation with minimum changes by means of high accessibility for capturing antibodies from the solution. 


\section{METHODOLOGY}

\section{Reagents}

Silver nitrate, hydroxylamine hydrochloride, sodium hydroxide, sodium chloride, potassium bromide and bovine serum albumin (BSA) were purchased from Sigma-Aldrich. LigA recombinant protein fused with GST (glutathione-S-transferase) was supplied by Dr Nobuo Koizumi, National Institute of Infectious Diseases, Japan. Both anti-leptospiral IgG antibody positive and negative human serum samples were provided by the Department of Microbiology, Faculty of Medicine, University of Peradeniya, Sri Lanka. Ethical clearance was not sought as the said serum samples were opted-in by patients for further use of diagnostic developments.

\section{Synthesis and characterisation of Ag NPs}

All laboratory glassware, magnetic stir bars and other equipment used in the experiment, were thoroughly washed with soap, in aqua regia $\left(\mathrm{HCl} / \mathrm{HNO}_{3} 3: 1, \mathrm{v} / \mathrm{v}\right)$ and with distilled water, respectively. Those were oven dried before usage to avoid undesirable nucleation during the analysis. Deionised (DI) water was used in all the experiments when necessary. Silver nanoparticles were synthesised according to Leopold and Lendl method (Leopold \& Lendl, 2003) using silver nitrate as the precursor and hydroxylamine hydrochloride containing sodium hydroxide as the reducing agent. Briefly, $90.00 \mathrm{~mL}$ of $1.67 \times 10^{-3} \mathrm{~mol} \mathrm{dm}^{-3}$ hydroxylamine hydrochloride aqueous solution containing $3.33 \times 10^{-3} \mathrm{~mol} \mathrm{dm}^{-3}$ sodium hydroxide was initially prepared at room temperature $\left(25^{\circ} \mathrm{C}\right)$, by maintaining the $\mathrm{pH}$ at $6.0,7.0,8.0$ and 9.0. Then, $10.00 \mathrm{~mL}$ of $1.00 \times 10^{-2} \mathrm{~mol} \mathrm{dm}^{-3}$ silver nitrate solution was added drop-wise to each solution under vigorous stirring on a magnetic stirrer at $25{ }^{\circ} \mathrm{C}$. Stirring was continued for additional $10 \mathrm{~min}$. The above procedure was repeated at $37{ }^{\circ} \mathrm{C}$ and the optimum temperature for the synthesis of silver nanoparticles was identified according to UV-visible spectroscopy (Shimadzu UV 1800 Series).

The characterisation of silver nanoparticles was done using particle size analysis (CILAS- Nano DS), scanning electron microscopy (ZEISSEVOLS15) and UV-visible spectroscopy. The nanoparticles were kept at $4{ }^{\circ} \mathrm{C}$ for further use. Further investigations were carried out at optimum temperature.
Optimisation of antigen concentration and environmental conditions for silver nanoparticle functionalisation

Initial concentration of recombinant LigA (leptospiral immunoglobulin-like protein A) was measured using the Nanodrop spectrophotometer (Thermo Scientific 2000). Different volumes of LigA (sample size, $n=6$ ) were added to Kahn tubes containing $4.00 \mathrm{~mL}$ of silver nanoparticles of $\mathrm{pH} 6.0,7.0,8.0$ and 9.0 to obtain a concentration series from $0.5-2.5 \mu \mathrm{g} \mathrm{mL}^{-1}$ (namely, $0.5,1.0,1.5,2.0$, and $2.5 \mu \mathrm{g} \mathrm{mL}^{-1}$ ) of the antigen at each $\mathrm{pH}$ level. The prepared samples were slightly vortexed and incubated at room temperature $\left(25^{\circ} \mathrm{C}\right)$ for $1 \mathrm{~h}$. Each sample was divided into two parts and one part was used to measure the absorbance using UV-visible spectrophotometer, while the other part was used for DLS measurement. Optimum $\mathrm{pH}$ level and LigA concentration were identified using the above UV-visible spectra and those results were further analysed using DLS.

DLS was used to screen the hydrodynamic diameter of particles. For this, $0.4 \mu \mathrm{g}$ of $10 \%$ (mass ratio) $\mathrm{NaCl}$ was added to each tube to verify the stability of nanoparticleprotein conjugates in saline environment (Genevieve et al., 2007). DLS measurements were taken before and after the salt addition for confirmation of optimum LigA concentration and optimum $\mathrm{pH}$ level, which were initially identified by UV-visible spectra. Further investigations were carried out at the above environmental conditions.

Further characterisation of samples was done using SEM and FT-IR (fourier transform-infrared) spectroscopy. In order to carryout SEM analysis, the samples were sonicated for $20 \mathrm{~min}$ in an ultrasonic bath to obtain an evenly dispersed solution by removing the aggregates. The samples were then placed on the sample stub and kept in an evaporation chamber for nearly $12 \mathrm{~h}$. Carbon tape was used afterwards to adhesively bind the samples to the stub and the samples were gold sputtered before the analysis. For FT-IR spectroscopy, the samples were freeze-dried and diluted with potassium bromide in 1:100 ratio. SEM produces the images of a sample by scanning the surface with a focused electron beam, while FT-IR spectroscopy is used to identify the changes in a protein structure. Proteins contain amide linkages between amino acid residues, which possess well known peaks in the infrared region. FT-IR spectrum of a complex protein is composed of many overlapping bands and important information can be hidden in those undistinguishable, broad absorption bands (Barth, 2007). BSA was used as a secondary stabiliser for the 
functionalised nanoparticles, thus, $0.25 \%$ BSA was added to the solution to achieve the required stability level. The nanoparticles can be stored at $4{ }^{\circ} \mathrm{C}$ for $4 \mathrm{wk}$ or at room temperature for $2 \mathrm{wk}$ for further use.

\section{Analysis of the sensitivity of LigA-functionalised silver nanoparticles}

For the determination of the presence or absence of $\mathrm{IgG}$ antibodies in human serum samples, Leptospira IgG ELISA and IFA were carried out to confirm the presence of anti-leptospiral IgG antibodies. Different volumes of human sera containing anti-leptospiral antibodies $(n=50)$ were added to Kahn tubes containing $4.00 \mathrm{~mL}$ of LigAfunctionalised silver nanoparticles (the diluent) to obtain a dilution series from 1:300 to 1:5 (namely, 1:300, 1:200, $1: 150,1: 100,1: 75,1: 50,1: 25,1: 20,1: 15,1: 10,1: 5)$ of the antibody. The solutions were allowed to incubate for $30 \mathrm{~min}$ at room temperature. The aggregation process was analysed by UV-visible spectroscopy and SEM.

\section{Evaluation of the specificity of LigA-functionalised silver nanoparticles}

In order to evaluate the specificity of conjugated nanoparticles, a control group of LigA-functionalised nanoparticles was tested with anti-leptospiral IgG antibody negative (previously tested with Leptospira IgG ELISA and IFA) serum samples $(n=20)$. Different volumes of serum were added to Kahn tubes containing $4.00 \mathrm{~mL}$ of LigA-functionalised silver nanoparticles to obtain a dilution series from 1:300 to 1:5 (namely, 1:300, $1: 200,1: 150,1: 100,1: 75,1: 50,1: 25,1: 20,1: 15,1: 10$, 1:5). Results were analysed by UV-visible spectroscopy.

\section{RESULTS AND DISCUSSION}

\section{Synthesis of silver nanoparticles}

Figure 1 represents the UV-visible absorption spectra of silver nanoparticles at $25^{\circ} \mathrm{C}$ and $37^{\circ} \mathrm{C}$.

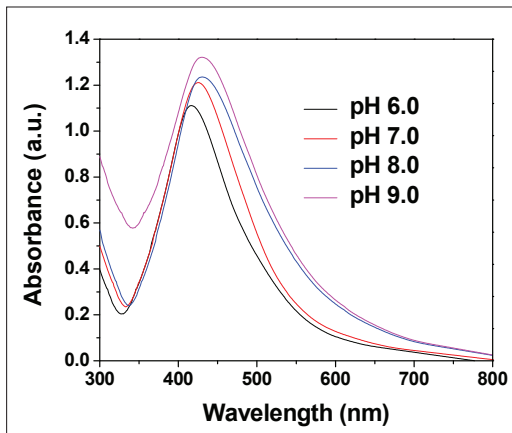

(a)

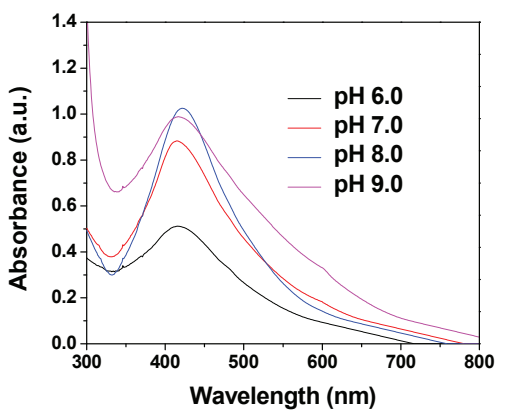

(b)

Figure 1: UV-visible absorption spectra of silver nanoparticles prepared at (a) $25{ }^{\circ} \mathrm{C}$ and (b) $37{ }^{\circ} \mathrm{C}$ at different $\mathrm{pH}$ levels.

Temperature has a great influence on the reactive kinetics of molecules. Herein, $25{ }^{\circ} \mathrm{C}$ and $37{ }^{\circ} \mathrm{C}$ were used to investigate the optimum temperature for the synthesis of silvernanoparticles. At $37^{\circ} \mathrm{C}$, relativelybroaderabsorption bands with decrement of absorbance were observed at different $\mathrm{pH}$ levels due to aggregation of particles at high temperature, which is shown in Figure 1 (b). Therefore, $25{ }^{\circ} \mathrm{C}$ was ideal for the functionalisation process as narrow absorption bands indicated the high stability of nanoparticles. The differences in absorption bands may be due to the increase in kinetic energy with temperature. Particles move faster at high temperatures and make more collisions. As a result, particles tend to aggregate, rather than forming a homogeneous solution.

\section{Functionalisation of silver nanoparticles with LigA} antigens

In order to attach proteins to the nanoparticle surface, proteins were added to the nanoparticle solution drop wise under vigorous stirring for nearly $30 \mathrm{~min}$ at room temperature. Upon the addition of LigA, the proteins get attached to the nanoparticle surface due to the interaction with hydroxylamine chloride ions. The optimum concentration of LigA to cover a full monolayer is known as critical concentration.

Below the critical concentration, nanoparticles are under-saturated, i.e. partially covered with antigens, 
whereas beyond the critical concentration, excess antigens are present in the solution and they can be loosely attached to the nanoparticle surface. At under-saturation level, many of the anti-leptospiral antibodies may not interact specifically with nanoparticles. At over-saturation level, antibodies get loosely attached to nanoparticles due to the presence of excess LigA. Therefore, it is crucial to obtain the saturation level of nanoparticles for further analysis using anti-leptospiral antibodies. The process of protein adsorption onto nanoparticle surface depends on several factors such as temperature and $\mathrm{pH}$ of the medium, concentration, isoelectric point of protein and ionic strength (Saha et al., 2014; Taghipour et al., 2018). Nevertheless, it is not possible to study all the above parameters simultaneously for the optimisation process.

The $\mathrm{pH}$ level of the medium affects the hydrogen bonds and overall charge of the protein. Exceedingly high or low $\mathrm{pH}$ cause changes in molecular conformation and the bioactivity. It is well-known that a $\mathrm{pH}$ equal or slightly above the isoelectric point (pI) of the protein is the optimum $\mathrm{pH}$ for adsorption of proteins to nanoparticle surface (Taghipour et al., 2018). For $\mathrm{pH}$ optimisation, the $\mathrm{pH}$ range was selected as $6.0-9.0$ as the $\mathrm{pI}$ of LigA protein is about 6.5. Different amounts of LigA were added to $\mathrm{pH}$ adjusted silver nanoparticles to obtain a concentration series of LigA from $0.5-2.5 \mu \mathrm{g} \mathrm{mL}^{-1}$ at each $\mathrm{pH}$ level. Figure 2 represents the surface plasmon resonance spectra of LigA functionalised silver nanoparticles at different $\mathrm{pH}$ levels.

The results are in agreement with the above mentioned statement as 7.0 was the optimal $\mathrm{pH}$ for protein adsorption, which was slightly above the respective pI. It has shown that the silver colloids of $\mathrm{pH}$ 6.0, 8.0 and 9.0 had unstable spectra with broad peaks, confirming particle aggregation compared to the silver colloids of $\mathrm{pH}$ 7.0. According to SPR spectra of $\mathrm{pH}$ 7.0, the highest absorption was obtained when the LigA concentration was $1.5 \mu \mathrm{g} \mathrm{mL}^{-1}$ and that shows the most similar spectrum to that of nanoparticles as well. Therefore, $1.5 \mu \mathrm{g} \mathrm{mL}^{-1}$ was taken as the optimal LigA concentration for the functionalisation. However, these results were further analysed using DLS.

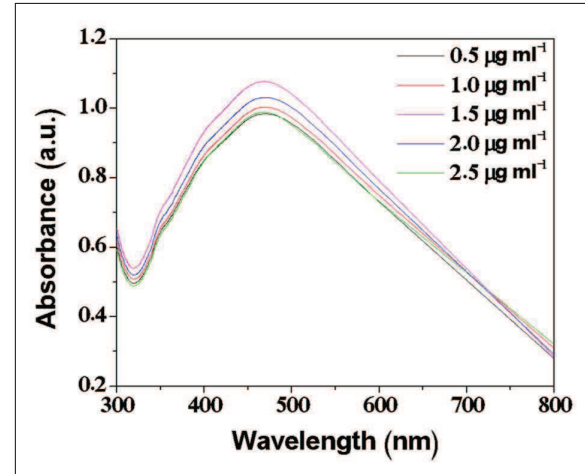

(a)

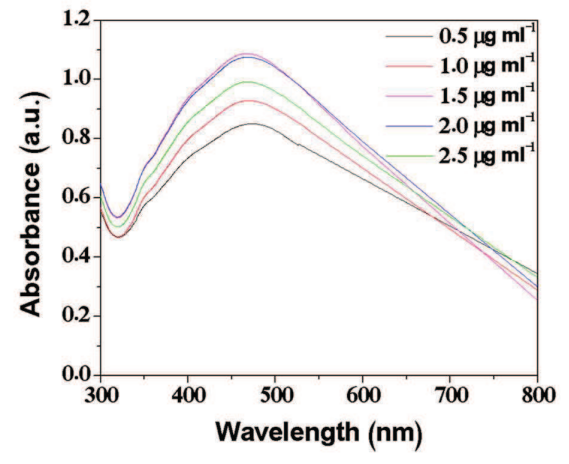

(c)

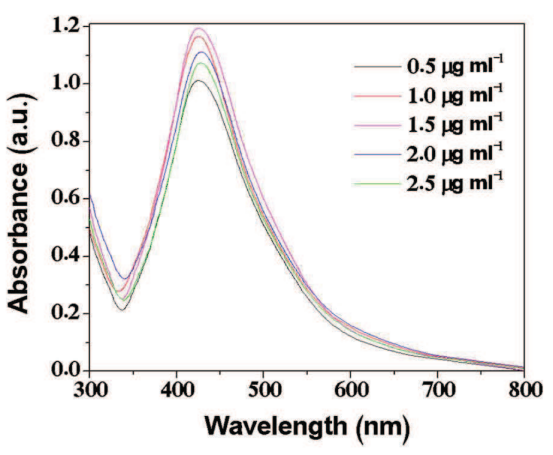

(b)

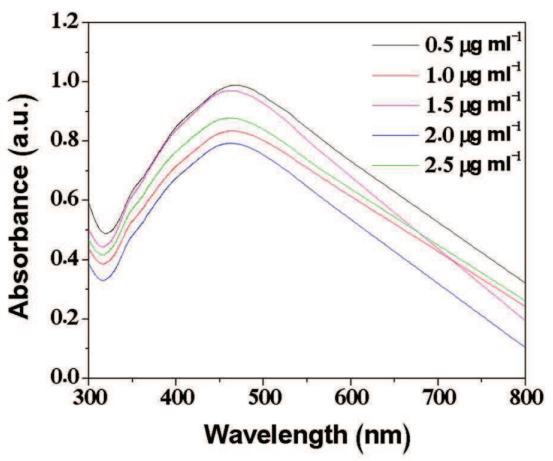

(d)

Figure 2: UV-visible absorption spectra of functionalised nanoparticles at $\mathrm{pH}$ levels of (a) 6.0, (b) 7.0, (c) 8.0 and (d) 9.0 
If a monolayer of LigA was coated on nanoparticle surface, $\mathrm{Na}^{+}$ions in saline solution would not attach to hydroxylamine chloride ions, thus, it will not affect the stability of the conjugate. If an insufficient amount of LigA was present, most of the nanoparticles would still be covered with hydroxylamine chloride ions. As a result, the negative charge of nanoparticles would be screened by counter $\mathrm{Na}^{+}$ions, causing agglomeration. Using this experiment, it is easy to determine the critical concentration by gradually increasing the LigA concentration from a low value where flocculation in $\mathrm{NaCl}$ solution occurs, to a high value where flocculation is prevented.

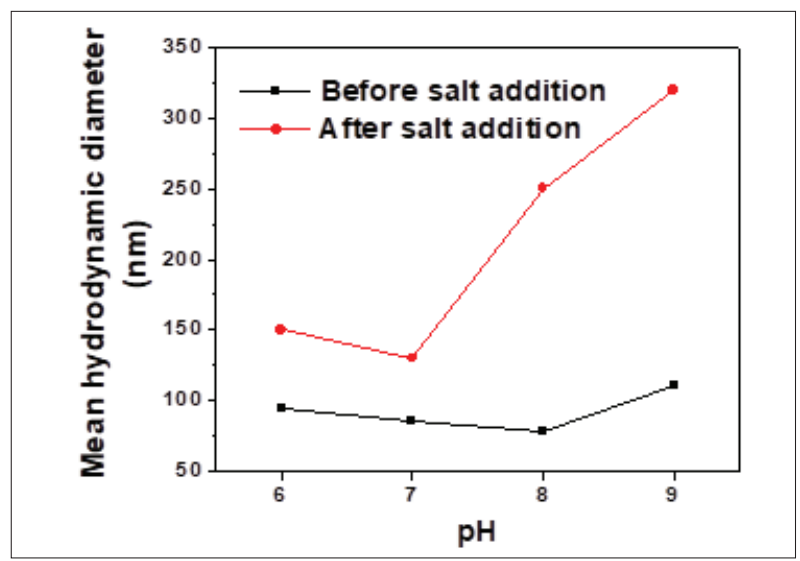

Figure 3: Mean hydrodynamic diameter of Ag NP-LigA conjugates (LigA concentration is $1.5 \mu \mathrm{g} \mathrm{mL}^{-1}$ ) as a function of $\mathrm{pH}$, before and after addition of $\mathrm{NaCl}$

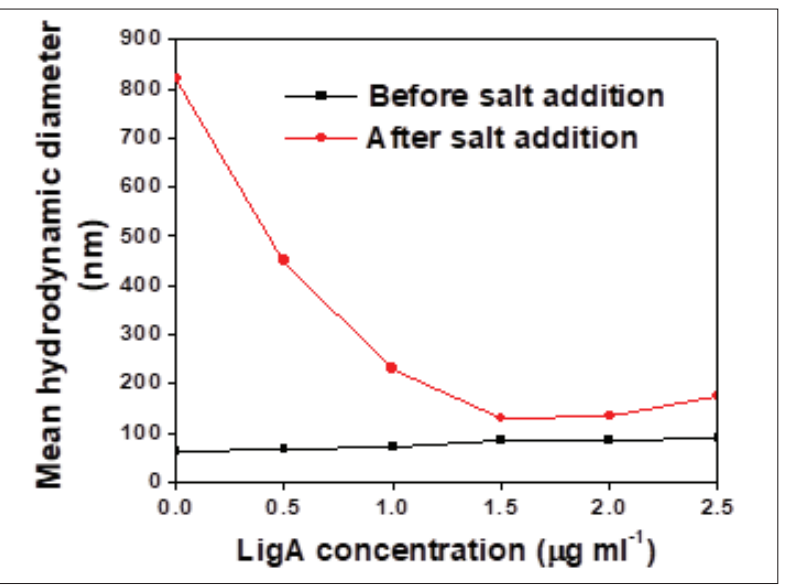

Figure 4: Mean hydrodynamic diameter of Ag NP-LigA conjugates ( $\mathrm{pH}$ of 7.0) as a function of LigA concentration, before and after addition of $\mathrm{NaCl}$
Figure 3 shows the adsorption curve plotted as mean $\mathrm{D}_{\mathrm{H}}$ (hydrodynamic diameter) versus $\mathrm{pH}$ with a fixed LigA concentration of $1.5 \mu \mathrm{g} \mathrm{mL}^{-1}$, before and after the addition of $\mathrm{NaCl}$. Correspondingly, Figure 4 shows mean $\mathrm{D}_{\mathrm{H}}$ of LigA functionalised nanoparticles at $\mathrm{pH}$ of 7.0 as a function of LigA concentration, followed by the addition of $\mathrm{NaCl}$.

The $\mathrm{D}_{\mathrm{H}}$ of plain silver nanoparticles was measured as $60 \mathrm{~nm}$. $\mathrm{D}_{\mathrm{H}}$ was enhanced upto around $90 \mathrm{~nm}$ due to the adsorption of antigens depending on LigA concentration. At $\mathrm{pH} 7.0$, only $1.5 \mu \mathrm{g}$ of LigA was required per $1 \mathrm{~mL}$ of nanoparticles to form a monolayer of antigen on nanoparticle surface. It is likely that the molecular conformation of LigA can form several contacts with the nanoparticle surface so that it rapidly reaches saturation with a minimal amount of antigen. The stability level was also maintained at high LigA concentrations. These results of antigen adsorption and conjugate stabilisation were further evaluated by the DLS aggregation curve taken after the addition of $\mathrm{NaCl}$. Flocculation had taken place in solutions with a lower concentration of LigA $\left(0.5\right.$ and $\left.1.0 \mu \mathrm{g} \mathrm{mL}^{-1}\right)$ due to the absence of a sufficient amount of LigA to stabilise the nanoparticles. Conversely, flocculation was prevented by the presence of relatively high quantities of LigA molecules, as they stabilise the nanoparticles by forming a surface coating.

$\mathrm{D}_{\mathrm{H}}$ of conjugated nanoparticles changes according to the $\mathrm{pH}$ of medium by $10 \mathrm{~nm}$ to $30 \mathrm{~nm}$ with respect to unconjugated nanoparticles. At lower $\mathrm{pH}$ level (6.0), the antigen has a net positive charge and the antigen itself destabilised the nanoparticle, inducing aggregation. As a result, $\mathrm{D}_{\mathrm{H}}$ is increased by $34 \mathrm{~nm}$. On the contrary, at $\mathrm{pH}$ level of $8.0, \mathrm{D}_{\mathrm{H}}$ was increased by only $18 \mathrm{~nm}$, where the antigen was negatively charged and a full monolayer of antigen was not adsorbed onto the negatively charged hydroxylamine chloride capped nanoparticle. However, at $\mathrm{pH} 9.0, \mathrm{D}_{\mathrm{H}}$ has increased by $50 \mathrm{~nm}$, as the extreme negative charge of LigA induced the aggregation of particles. $\mathrm{NaCl}$ was then added to investigate the antigen adsorption and subsequent stabilisation in solutions of high ionic strength. According to Figure 4 , the $\mathrm{D}_{\mathrm{H}}$ of antigen-nanoparticle conjugate has increased at extreme $\mathrm{pH}$ levels after the addition of $\mathrm{NaCl}$, confirming that not enough antigens got adsorbed onto the nanoparticle surface to stabilise the nanoparticles. The antigennanoparticle conjugate was least affected by the electrolytes at $\mathrm{pH}$ 7.0, stabilising the nanoparticles by forming a full monolayer of antigens. 
Thus, the DLS data were consistent with the UV-visible spectrometric data, confirming the optimal $\mathrm{pH}$ level of 7.0 and optimal LigA concentration of $1.5 \mu \mathrm{g} \mathrm{mL}^{-1}$ for the functionalisation of silver nanoparticles.
Figure 5 represents the SEM image and UV-visible absorption spectrum of silver nanoparticles. The mean diameter of the synthesised nanoparticles was $60 \mathrm{~nm}$ with a surface plasmon resonance peak at $425 \mathrm{~nm}$.

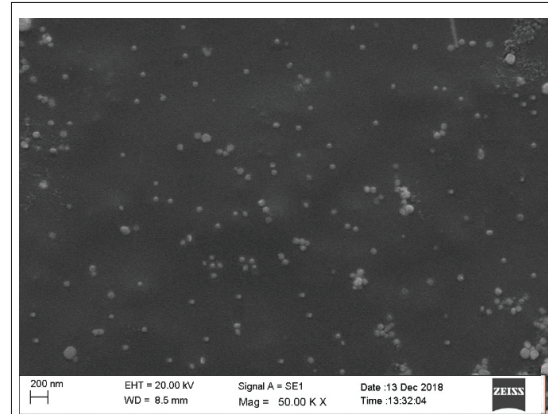

(a)

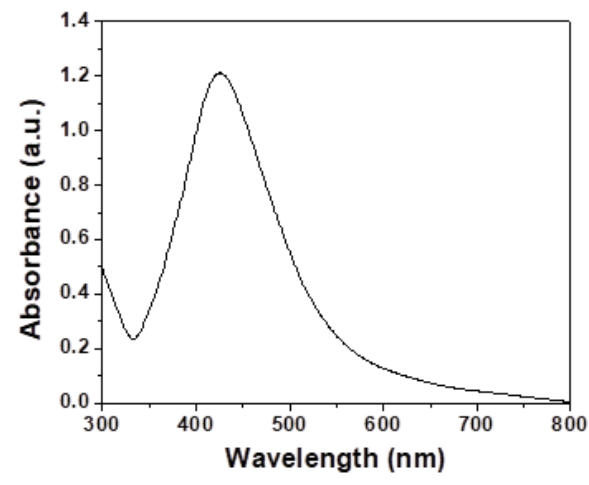

(b)

Figure 5: (a) SEM image and (b) UV-visible absorption spectrum of silver nanoparticles

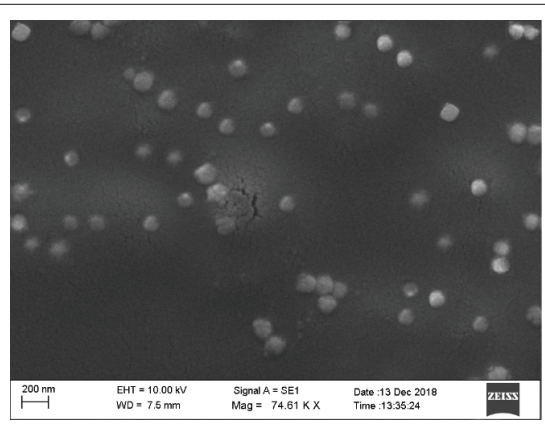

(a)

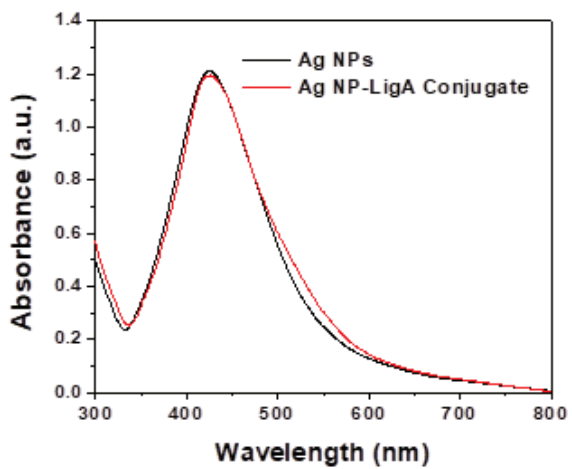

(b)

Figure 6: (a) SEM image and (b) UV-visible absorption spectrum of LigA-functionalised silver nanoparticles at $\mathrm{pH}$ of 7.0 and $25^{\circ} \mathrm{C}$

Figure 6 represents the SEM image and UV-visible absorption spectrum of LigA functionalised silver nanoparticles at optimal environmental conditions $(\mathrm{pH}$ 7.0 and $25^{\circ} \mathrm{C}$ ). However, according to the SEM image, the mean diameter of the functionalised nanoparticles was $110 \mathrm{~nm}$. The surface plasmon resonance peak of functionalised nanoparticles was observed at $428 \mathrm{~nm}$.

LigA functionalisation was further identified using the characteristic transmission peaks of the protein in FT-IR spectrum (Figure 7).
Bending vibrations of amide I and amide II bands of the protein were observed at $1642 \mathrm{~cm}^{-1}$ and $1540 \mathrm{~cm}^{-1}$ respectively, while the bands at $3373 \mathrm{~cm}^{-1}$ and $2956 \mathrm{~cm}^{-1}$ correspond to the stretching vibrations of amide I and amide II, respectively (Jain et al., 2011). The two bands seen at $1040 \mathrm{~cm}^{-1}$ and $1359 \mathrm{~cm}^{-1}$ can be assigned to $\mathrm{C}-\mathrm{N}$ stretching vibrations of aliphatic and aromatic amines, respectively (Vigneshwaran et al., 2006).

Generally, the protein can get directly adsorbed onto nanoparticle surface or the nanoparticle-protein 
interaction can take place through cysteine residues or free amine groups or the electrostatic interactions with negatively charged carboxylate groups (Gole et al., 2001). There were no peaks in between $2550-$ $2600 \mathrm{~cm}^{-1}$ confirming the absence or the presence of an arbitrary amount of S-H bonds, thus cysteine in the protein. In LigA-functionalised nanoparticle sample, enhanced signals of amide I and amide II bands can be observed. Further, IR bands associated with
- $\mathrm{COO}^{-}$groups had appeared, including the symmetric/ asymmetric stretching vibration of - $\mathrm{COO}^{-}$groups which were overlapped with the amide II band at $1564 \mathrm{~cm}^{-1}$, $-\mathrm{COO}^{-}$rocking and scissoring at $830 \mathrm{~cm}^{-1}$ and $870 \mathrm{~cm}^{-1}$, respectively and $-\mathrm{C}=\mathrm{O}$ out of plane bending at $770 \mathrm{~cm}^{-1}$ (Rehman et al., 2010). With the increase in intensities of these bands, it can be assumed that the carboxylic groups are highly exposed at pH 7.0 (Xu et al., 2014).

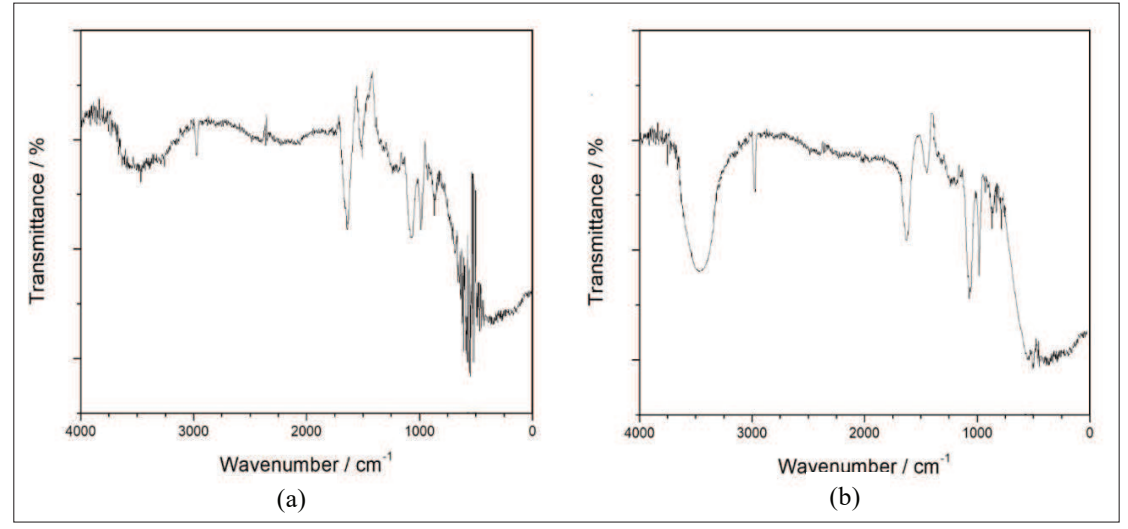

Figure 7: FT-IR spectra of (a) pure LigA protein and (b) LigA-functionalised silver nanoparticles

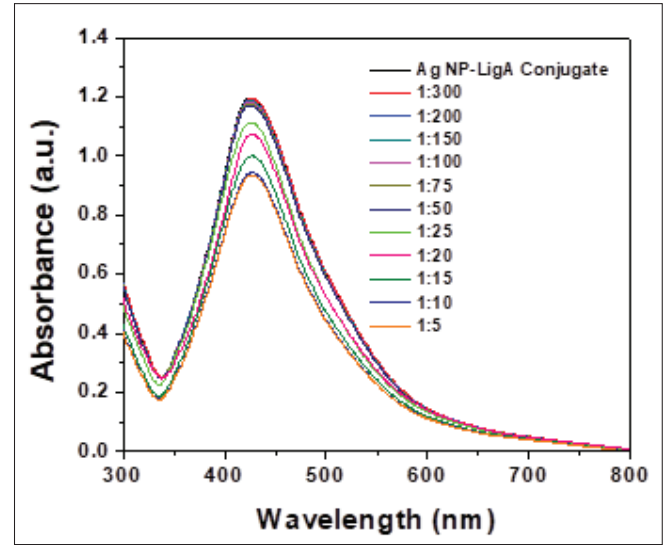

Figure 8: UV-visible absorption spectra of LigAfunctionalised silver nanoparticles upon the dilution of anti-leptospiral antibodies from $1: 300$ to $1: 5$

It was stated earlier that $110 \%$ of the minimum required amount of protein is appropriate for conjugate stabilisation (Saha et al., 2014). Generally, it is more favourable to use a secondary stabiliser such as bovine serum albumin (BSA) to obtain a higher stability level of the conjugate in saline environment for a long storage time (Zhang et al., 2014; Taghipour et al., 2018). Therefore, $0.25 \%$ of BSA was added to the colloidal silver conjugate to achieve the highest stabilisation level. There was no significant increase in size indicating that the conjugate was stable in saline environment.

\section{Detection of the sensitivity of LigA-functionalised silver nanoparticles towards anti-leptospiral antibodies}

In order to evaluate the sensitivity of LigA functionalised silver nanoparticles, they were tested with antileptospiral IgG antibodies. Figure 8 demonstrates the UV-visible absorption upon addition of different amounts of $\operatorname{IgG}$ antibody to the nanoparticle conjugate to obtain a dilution series of antibody. The dilution of 1:300 to $1: 50$ of $\operatorname{IgG}$ antibodies maintained no response compared to the nanoparticle conjugate. Subsequently, after 1:25 dilution of IgG antibody, the absorption started to decrease upto 1:10. After that, the system started to saturate, thus, absorption became static. According to these results (Figure 9), sensitivity of the biosensor based on LigA-functionalised silver nanoparticles is acquired to be 1:25 (mean absorbance $=1.113 ; \mathrm{SD}= \pm 0.047$; $95 \% \mathrm{CI}=1.100-1.126)$. 


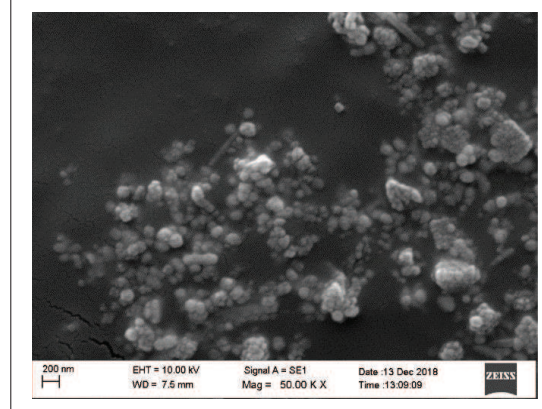

(a)

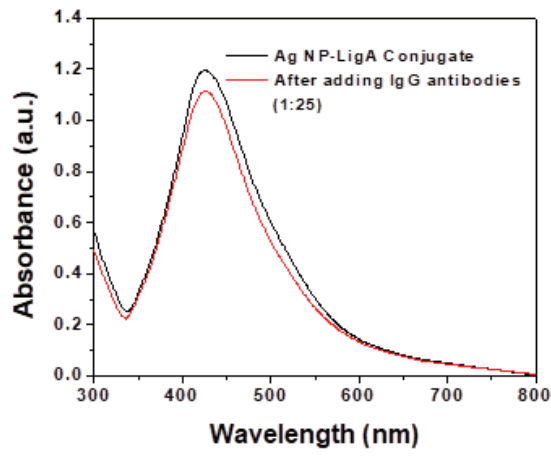

(b)

Figure 9: (a) SEM image and (b) UV-visible absorption spectrum of LigA-functionalised silver nanoparticles upon the addition of anti-leptospiral $\operatorname{IgG}$ antibodies (1:25 dilution)

\section{Detection of the specificity of LigA-functionalised silver nanoparticles}

Furthermore, for the determination of the specificity of the nanoparticle conjugate, they were tested with human serum samples which did not contain anti-leptospiral antibodies. The non-responsive spectra of UV-visible absorption are shown in Figure 10 (mean absorbance $=1.180 ; \mathrm{SD}= \pm 0.012 ; 95 \% \mathrm{CI}=1.177-1.183)$. According to these results, it can be confirmed that LigA-functionalised silver nanoparticles were specific to anti-leptospiral antibodies in human sera.

\section{Clinical applications}

The LSPR biosensor can be easily utilised to detect IgG antibodies in humans within a shorter screening time. The biosensor needs only a few raw materials to develop and does not require any washing steps or incubation steps in the assay. The results overlap with those of other diagnostic methods, i.e. ELISA or IFA, confirming the accuracy of the method. IgG antibody detection can be performed as a one-step assay, where each batch of samples requires the readings of positive and negative anti-leptospiral IgG serum samples, similar to ELISA, to compare with the test samples. This is the initial step of a promising assay, which can be expanded to detect antileptospiral IgM antibodies in recently infected patients of leptospirosis. It is anticipated that this LSPR biosensor can be exploited to detect various proteins by selected nanoparticle-antigen conjugates, which makes the new sensor capable of detecting a wide variety of antibodies. As the next step, the biosensor can be developed to detect and quantify anti-leptospiral $\operatorname{IgM}$ antibodies, adhering to the same protocol, which can be used clinically for acute diagnosis. This is extremely important for endemic countries, such as Sri Lanka, to precisely determine the infection.

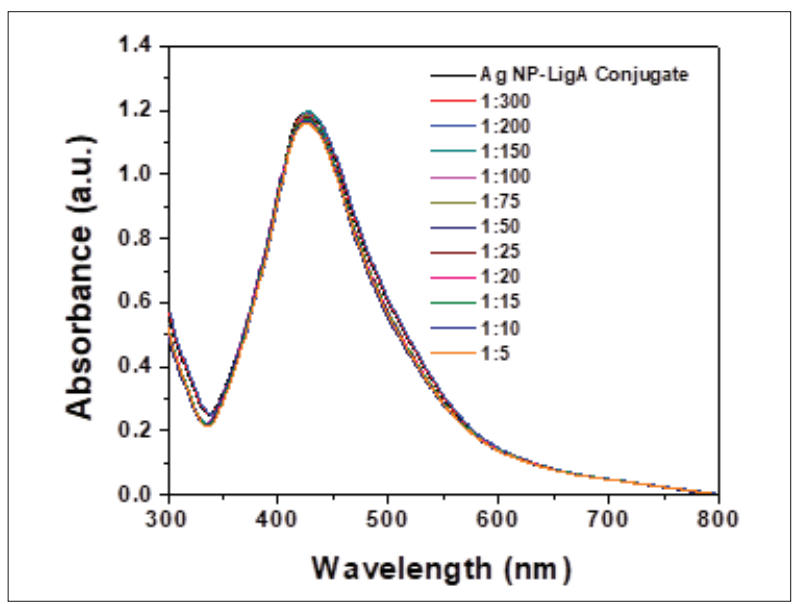

Figure 10: UV-visible absorption spectra of LigA-functionalised silver nanoparticles upon the dilution of anti-leptospiral antibody negative serum samples from 1:300 to 1:5

\section{CONCLUSIONS}

In this study, a biosensor based on LigA-functionalised silver nanoparticles was prepared using a straightforward protocol for the detection of anti-leptospiral $\mathrm{IgG}$ antibodies in human sera. The main goal of this project was to optimise the essential factors which had a major impact on nanoparticle-antigen conjugation, such as $\mathrm{pH}$, temperature and protein concentration. This LSPR biosensor shows a positive response to anti-leptospiral 
IgG protein at $\mathrm{pH} 7.0$ and $25{ }^{\circ} \mathrm{C}$ in dilutions lower than 1:25. This novel technique offers substantial improvement in terms of screening time compared to conventional methods. The results can be investigated using UV-visible spectroscopy as a single-step detection method.

This study has been performed with certain limitations. The number of samples anti-leptospiral $\mathrm{IgG}$ antibodies was limited to 50, while the number of samples of anti-leptospiral IgG antibody negative sera was limited to 20 . As the next step, the developed antigen-nanoparticle conjugate can be tested with antibodies of other clinically similar infectious diseases such as Hantavirus, hepatitis and malaria to increase the specificity. Furthermore, the study should report the kinetics of immobilised proteins to identify the rate of antibody-capturing activity of antigens. This can be achieved by analysing small amounts of the sample at regular time intervals for antibodies. Nevertheless, a comprehensive study to analyse the total number of active antigens and the kinetics of antibody capturing is not yet identified.

\section{Acknowledgement}

The authors thank Dr Nobuo Koizumi, National Institute of Infectious Diseases, Tokyo, Japan for providing recombinant LigA fused with GST (glutathione-Stransferase).

\section{REFERENCES}

Barth A. (2007). Infrared spectroscopy of proteins. Biochimica et Biophysica Acta - Bioenergetics 1767(9): 1073-1101. DOI: https://doi.org/10.1016/j.bbabio.2007.06.004

Blackman J. A. (2008). Photoexcitation and optical absorption. In: Handbook of Metal Physics, volume 5, chapter 7, pp. 175-229. Elsevier B.V., UK.

DOI: https://doi.org/10.1016/S1570-002X(08)00207-3

Budihal S. V. \& Perwez K. (2014). Leptospirosis diagnosis: competency of various laboratory tests. Journal of Clinical and Diagnostic Tests 8(1): 199-202.

DOI: https://doi.org/10.7860/JCDR/2014/6593.3950

Chirathaworn C., Inwattana R., Poovorawan Y. \& Suwancharoen D. (2014). Interpretation of microscopic agglutination test for leptospirosis diagnosis and seroprevalence. Asian Pacific Journal of Tropical Biomedicine 4(1): S162-S164. DOI: https://doi.org/10.12980/APJTB.4.2014C580

Cosson J.F., Picardeau M., Mielcarek M., Tatard C., Chaval Y., Suputtamongkol Y., Buchy P., Jittapalapong S., Herbreteau V. \& Morand S. (2014). Epidemiology of leptospira transmitted by rodents in Southeast Asia, PLOS Neglected Tropical Diseases 8(6): 1-10.

DOI: https://doi.org/10.1371/journal.pntd.0002902
Fraga T., Carvalho E., Isaac L. \& Barbosa A. (2014). Leptospira and Leptospirosis. Molecular Medical Microbiology 2(3): 1973-1990.

DOI: https://doi.org/10.1016/B978-0-12-397169-2.00107-4

Genevieve M., Vieu C., Carles R., Zwick A., Briere G., Salome L. \& Trevisiol E. (2007). Biofunctionalization of gold nanoparticles and their spectral properties. Microelectronic Engineering 84(5): 1710-1713.

DOI: https://doi.org/10.1016/j.mee.2007.01.247

George J.M., Antony A. \& Mathew B. (2018). Metal oxide nanoparticles in electrochemical sensing and biosensing: a review. Microchim Acta 185(7): 358.

DOI: https://doi.org/10.1007/s00604-018-2894-3

Gole A., Dash C., Ramakrishnan V., Sainkar S.R., Mandale A.B., Rao M. \& Sastry M. (2001). Pepsin-gold colloid conjugates: preparation, characterization, and enzymatic activity. Langmuir 17(5): 1674-1679.

DOI: https://doi.org/10.1021/la001164w

Hola K., Markova Z., Zoppellaro G., Tucek J. \& Zboril R. (2015). Tailored functionalization of iron oxide nanoparticles for MRI, drug delivery, magnetic separation and immobilization of biosubstances. Biotechnology Advances 33(6): 1162-1176.

DOI: https://doi.org/10.1016/j.biotechadv.2015.02.003

Hong Y., Huh Y., Yoon D.S. \& Yang J. (2012). Nanobiosensors based on localized surface plasmon resonance for biomarker detection. Journal of Nanomedicine 2012(1): 1-13. DOI: https://doi.org/10.1155/2012/759830

Jain N., Bhargava A., Majumdar S., Tarafdar J.C. \& Panwar J. (2011). Extracellular biosynthesis and characterization of silver nanoparticles using Aspergillus flavus NJP08: a mechanism perspective. Nanoscale 3(2): 635-641. DOI: https://doi.org/10.1039/C0NR00656D

Karunaratne R.E., Wijenayaka L.A., Wijesundera S.S., De Silva K.M.N., Adikaram C.P. \& Perera J. (2019). Use of nanotechnology for infectious disease diagnostics: application in drug resistant tuberculosis. BMC Infectious Diseases 19(618): 1-9.

DOI: https://doi.org/10.1186/s12879-019-4259-x

Khaki P. (2016). Clinical laboratory diagnosis of human leptospirosis. International Journal of Enteric Pathogens 4(1): $1-7$.

DOI: https://doi.org/10.17795/ijep31859

Kumari P., Ghosh B. \& Biswas S. (2016). Nanocarriers for cancer-targeted drug delivery. Journal of Drug Targeting 24(3): 179-191.

DOI: https://doi.org/10.3109/1061186X.2015.1051049

Leopold N. \& Lendl B. (2003). Anew method for fast preparation of highly surface-enhanced Raman scattering (SERS) active silver colloids at room temperature by reduction of silver nitrate with hydroxylamine hydrochloride. The Journal of Physical Chemistry B 107(24): 5723-5727. DOI: https://doi.org/10.1021/jp027460u

Maiyo F. \& Singh M. (2017). Selenium nanoparticles: potential in cancer gene and drug delivery. Nanomedicine 12: 10751089.

DOI: https://doi.org/10.2217/nnm-2017-0024

Manatunga D.C., De Silva R.M. \& De Silva K.M.N. (2018). 
The state of nanomedicine in Sri Lanka: challenges and opportunities. Journal of Interdisciplinary Nanomedicine 3(2): 32- 37.

DOI: https://doi.org/10.1002/jin2.38

Nikalje A.P. (2015). Nanotechnology and its applications in medicine. Medicinal Chemistry 5(2): 81-89. DOI: https://doi.org/10.4172/2161-0444.1000247

Pappas G., Papadimitriou P., Siozopoulou V., Christou L. \& Akritidis N. (2008). The globalization of leptospirosis: worldwide incidence trends. International Journal of Infectious Diseases 12(4): 351-357.

DOI: https://doi.org/10.1016/j.ijid.2007.09.011

Patra et al. (12 authors) (2018). Nano based drug delivery systems: recent developments and future prospects. Journal of Nanobiotechnology 16(71): 1-33. DOI: https://doi.org/10.1186/s12951-018-0392-8

Priyanka S., Shashank P., Aslam M.K.M., Prashant S. \& Pal S.K. (2013). Nanobiosensors: diagnostic tool for pathogen detection. International Research Journal of Biological Sciences 2(10): 76-84.

Rehman S., Movasaghi Z., Darr J. \& Rehman I. (2010). Fourier transform infrared spectroscopic analysis of breast cancer tissues; identifying differences between normal breast, invasive ductal carcinoma, and ductal carcinoma in situ of the breast. Applied Spectroscopy Reviews 45(5): 355-368. DOI: https://doi.org/10.1080/05704928.2010.483674

Saha B., Evers T.H. \& Prins M.W.J. (2014). How antibody surface coverage on nanoparticles determines the activity and kinetics of antigen capturing for biosensing. Analytical Chemistry 86(16): 8158-8166.

DOI: https://doi.org/10.1021/ac501536z

Soloviev M. (2004). Applications of nanoparticles in biology and medicine. Journal of Nanobiotechnology 5(3): 3-5. DOI: https://doi.org/10.1186/1477-3155-5-11

Taghipour Y.D., Kharrazi S. \& Amini S.M. (2018). Antibody conjugated gold nanoparticles for detection of small amounts of antigen based on surface plasmon resonance (SPR) spectra. Nanomedicine Research Journal 3(2):
$102-108$.

DOI: https://doi.org/10.22034/nmrj.2018.02.007

Toyokawa T., Ohnishi M. \& Koizumi N. (2011). Diagnosis of acute leptospirosis. Expert Review of Anti-Infective Therapy 9(1): 111-121.

DOI: https://doi.org/10.1586/eri.10.151

Vigneshwaran N., Kathe A.A., Varadarajan P.V., Nachane R.P. \& Balasubramanya R.H. (2006). Biomimetics of silver nanoparticles by white rot fungus, Phaenerochaete chrysosporium. Colloids and Surfaces B: Biointerfaces 53(1): 55-59.

DOI: https://doi.org/10.1016/j.colsurfb.2006.07.014

Wais U., Jackson A.W., He T. \& Zhang H. (2016). Nanoformulation and encapsulation approaches for poorly water-soluble drug nanoparticles. Nanoscale 8(4): 1746-1769.

DOI: https://doi.org/10.1039/C5NR07161E

Wang Z., Ruan J. \& Cui D. (2009). Advances and prospect of nanotechnology in stem cells. Nanoscale Research Letters 4(7): 593-605.

DOI: https://doi.org/10.1007/s11671-009-9292-z

Watkins R., Wu L., Zhang C., Davis R.M. \& Xu B. (2015). Natural product-based nanomedicine: recent advances and issues. International Journal of Nanomedicine 10(1): 6055-6074.

DOI: https://doi.org/10.2147/IJN.S92162

WHO (2003). Human leptospirosis: guidance for diagnosis, surveillance and control. WHO Library 45(5): 1-109. DOI: https://doi.org/10.1590/S0036-46652003000500015

Xu Y., Sherwood J., Qin Y., Crowley D., Bonizzoni M. \& Bao Y. (2014). The role of protein characteristics in the formation and fluorescence of $\mathrm{Au}$ nanoclusters. Nanoscale 6(3): 1515-1524.

DOI: https://doi.org/10.1039/C3NR06040C

Zhang S., Moustafa Y. \& Huo Q. (2014). Different interaction modes of biomolecules with citrate-capped gold nanoparticles. ACS Applied Materials and Interfaces 6(23): 21184-21192.

DOI: https://doi.org/10.1021/am506112u 